\title{
PROTOCOLOS DE PREPARACIÓN DE ESPORAS DE MICORRIZA ARBUSCULAR PARA SU OBSERVACIÓN EN MICROSCOPIO ELECTRÓNICO Y DE FLUORESCENCIA
}

\section{PROTOCOLS FOR THE OBSERVATION OF ARBUSCULAR MYCORRHIZAL SPORES UNDER THE SCANNING ELECTRON MICROSCOPE AND FLUORESCENCE MICROSCOPE}

\author{
Emilia Monserrat Ortiz \\ Departamento de Ciencias de la Vida, Universidad de las Fuerzas Armadas - \\ ESPE, Sangolquí, Ecuador, e-mail: emortiz1@espe.edu.ec \\ David Moisés Ramírez Coral \\ Departamento de Ciencias de la Vida, Universidad de las Fuerzas Armadas - \\ ESPE, Sangolquí, Ecuador, e-mail: dmramirez@espe.edu.ec
}

\begin{abstract}
Alexis Debut
Centro de Nanociencia y Nanotecnología, Universidad de las Fuerzas Armadas ESPE, Sangolquí, Ecuador, e-mail: apdebut@espe.edu.ec

\section{María José Vallejo-López}

Laboratorios de Nanomedicina y Nanobiología, Centro de Nanociencia y Nanotecnología y Departamento de Ciencias de la Vida, Universidad de las Fuerzas Armadas - ESPE, Sangolquí, Ecuador, email: mjvallejo2@espe.edu.ec

\section{Jessica Duchicela}

Departamento de Ciencias de la Vida, Universidad de las Fuerzas Armadas ESPE, Sangolquí, Ecuador, e-mail: jiduchicela@espe.edu.ec
\end{abstract}

\section{RESUMEN}

El objetivo del presente estudio fue desarrollar protocolos base de preparación de esporas de micorriza arbuscular (MA) para su observación en el microscopio electrónico de barrido (MEB) y de tinción vital basada en la reacción enzimática con Diacetato de Fluoresceína (FDA). La microscopía electrónica es una de las técnicas más utilizadas para la caracterización morfológica de esporas de 
MA; no obstante, los protocolos reportados en trabajos previos no son descritos a detalle y tampoco son válidos para todos los tipos de muestras. Para evaluar la vitalidad de las esporas de MA, se emplean colorantes vitales como el FDA, el mismo que es convertido a un producto fluorescente por la actividad de diferentes enzimas localizadas en la membrana celular. En este trabajo se empleó un protocolo de limpieza de esporas con una solución de Tween 20 (3.75\% V/V) y un proceso de deshidratación en un desecador de vidrio para su observación en el MEB. Adicionalmente, se trató las esporas con una solución de FDA $(25 \mu \mathrm{M})$ para observarlas en el microscopio de fluorescencia y determinar su vitalidad. El protocolo de preparación utilizado para la visualización de las esporas de MA con el MEB nos permitió observar todas las estructuras. En cuanto a la tinción vital, se concluyó que el método es efectivo para esporas producidas in vitro y que no se encuentran en estado de latencia.

Palabras Claves: Esporas de MA, HMA, morfología, vitalidad, diacetato de fluoresceína, fluorescencia, MEB, microscopio de fluorescencia, tinción vital

\section{ABSTRACT}

The aim of the present study was to develop new basic protocols for the observation of AM spores under scanning electron microscope (SEM) and vital staining based on enzymatic reaction of Fluorescein Diacetate (FDA). Electron microscopic techniques are frequently used to characterize the morphology of spores, however, there are not well described pre-established protocols. To assess the vitality of MA spores, vital dyes such as FDA are used. This compound is converted to a fluorescent product by the intracellular activity of different enzymes. In this work, a spore cleaning protocol was performed with a Tween 20 solution $(3.75 \% \mathrm{~V} / \mathrm{V})$ and a dehydration process in a glass desiccator was carried out for SEM observations. Furthermore, spores were treated with a FDA solution $(25 \mu \mathrm{M})$ in order to visualize them in the fluorescence microscope and determinate their vitality. The protocol for the observation of spores under the SEM allow to visualize all its structures without alterations. As for vital staining, it was concluded that the method is effective for spores produced in vitro and when they are not in latency state.

Keywords: AM spores, morphology, vitality, fluorescein diacetate, fluorescence, SEM, fluorescence microscope, vital staining

\section{INTRODUCCIÓN}

Los hongos micorrízicos arbusculares (HMA) son microorganismos que forman interacciones mutualistas con la mayoría de plantas (angiospermas, gimnospermas, briofitas y pteridofitas). Se consideran asociaciones simbióticas 
debido a que los hongos se benefician de las fuentes carbonadas provenientes de la planta, mientras que esta última se beneficia en la supervivencia, productividad (Goverde et al., 2000), capacidad reproductiva (Xiaohong y Koide, 1994), incremento en la tolerancia a situaciones de estrés debido a la presencia de metales pesados y escasez de nutrientes (Stahl y Smith, 1984). Se considera una asociación de distribución universal porque se han detectado en la rizósfera de la mayoría los hábitats naturales (Remy et al., 1994).

Las estructuras de reproducción asexual de hongos micorrízicos son las esporas, las cuales poseen miles de núcleos donde almacenan la información genética (Marleau et al., 2011) y se producen blásticamente en la punta del esporangio de la hifa. El número de esporas producidas depende de la especie de hongo, tipo de planta, fertilidad del suelo, aplicación de fertilizantes y pesticidas, fenología del hospedero, intensidad de la luz y competitividad de otras especies de MA (Koske, 1985).

El ciclo de desarrollo de las esporas difiere significativamente en el filo Glomeromycota, por esta razón, estas estructuras son consideradas fundamentales en la descripción taxonómica de hongos micorrízicos (Blaszkowski, 2003). Son ampliamente utilizadas en la propagación de MA (Marleau et al., 2011); sin embargo, el éxito de la germinación depende principalmente de la vitalidad de las esporas. Todos estos aspectos han motivado estudios de morfología y vitalidad de las esporas de MA.

\section{Observación de esporas de MA utilizando MEB}

La microscopía electrónica se considera una disciplina técnicamente exigente, debido a que los procedimientos para el manejo de los equipos y preparación de las muestras se rigen a muchas leyes absolutas. Por estas razones, los métodos para la preparación de las muestras, especialmente de tejidos y células, no se encuentran totalmente comprendidos; sin embargo, la información existente permite a los investigadores realizar modificaciones de procedimientos descritos en trabajos previos de acuerdo a sus necesidades (Dykstra y Reuss, 2003).

Se han descrito numerosos protocolos de observación de MA utilizando el MEB, los cuales intentan reducir la presencia de artefactos (suciedad, ruido electrónco) y mejorar la calidad de la imagen (Meijering et al., 2016). Dentro de las técnicas más utilizadas se encuentran: secado de punto crítico y secado por criofijación. El primer método puede encoger y deformar ciertas estructuras, las mismas que son conservadas con la criofijación debido a que el agua es vitrificada (Refshauge et al., citado por Unda, 2015). La desventaja de esta última técnica es el tiempo que toma la preparación de la muestra ya que emplea procesos tales como: liofilización por 24 horas, deshidratación en soluciones ascendentes de etanol 
(desde $30 \%$ hasta 99\%) durante 45 minutos en cada concentración, fijación con glutaraldehído por 1 hora y post fijación en $\mathrm{OsO}_{4}$ al 1\% durante 1 hora (Unda, 2015).

\section{Tinción vital de esporas de MA}

Uno de los avances más importantes dentro de las tecnologías ópticas del último siglo, fue la introducción de colorantes vitales para observar regiones y compartimentos celulares específicos. El uso de estas tinciones permite diferenciar células muertas y vivas basadas en la existencia o no de coloración de ciertos componentes celulares. La diversidad de células en las que se pueden emplear colorantes vitales se ha expandido rápidamente; sin embargo, muchos de los métodos usados comúnmente no son eficientes cuando se aplican en hongos por diversas razones. Por ejemplo, los colorantes DAPI y Hoescht 33258 empleados para teñir núcleos de células animales y vegetales no pueden utilizarse en hongos debido a que poseen un bajo contenido de ADN y la intensidad de fluorescencia puede ser variable (Savidge y Pothoulakis, 2005; Singh y Singh, 1995). Las microinyecciones son otro método por el cual se puede introducir colorantes en las células, no obstante, ha sido muy difícil reproducirlas en hongos debido al pequeño tamaño de las hifas y altas presiones de turgencia intracelular (Savidge y Pothoulakis, 2005).

Para evaluar la vitalidad de las esporas de MA se han desarrollado una diversidad de métodos como la estimación del NMP (Número Más Probable), pruebas de germinación y técnicas de tinción. El uso de tinciones vitales presenta ventajas en cuanto al ahorro de tiempo y trabajo. Varias sales de tetrazolio incluidas el INT (2-(4-iodophenyl)-3-(4-nitrophenyl)-5-phenyl-2H-tetrazolium chloride) y MTT (3-(4,5-dimethylthiazol-2-yl)-2,5-diphenyltetrazolium bromide) son ampliamente utilizadas para estimar la vitalidad de las esporas. De manera similar, el Diacetato de Fluoresceína (FDA) ha sido empleado en varias especies de MA, proporcionando buenos resultados (Bansal y Mukerji, 2002).

EI FDA es un compuesto no fluorescente que penetra la membrana intacta de las células y es hidrolizado por diferentes enzimas, tales como proteasas, lipasas y estereasas. El producto de esta conversión enzimática es la fluoresceína, que es observada dentro de las células con un microscopio de fluorescencia, o a su vez es cuantificada con un espectrofotómetro (Schnûrer y Rosswall, 1982). De manera que, es necesaria una integridad de membrana para la retención intracelular de la fluoresceína; las células no vitales son incapaces de hidrolizar el FDA o retener su producto enzimático (Flores et al., 2003) .

Esta técnica se ha reportado en la evaluación de inóculos de MA, fumigación del suelo, estudios de latencia, aplicaciones agrícolas y de biorremediación (Bansal y Mukerji, 2002). El análisis microscópico de las esporas no permite identificar este parámetro debido a que las esporas no viables (parasitadas, viejas o con una pared 
muy fina) pueden mantenerse visualmente normales durante largos períodos de tiempo. De la misma manera, una espora que parece normal puede no germinar por encontrarse en estado de latencia (Bansal y Mukerji, 2002). Por lo tanto, el uso de tinciones vitales proporcionan una herramienta muy poderosa para determinar la vitalidad de las esporas de MA.

Pese a que se han realizado numerosos estudios que definen protocolos para observar la morfología (criofijación, punto crítico) y determinar la vitalidad de esporas de MA (tinciónes vitales, número más probable, porcentaje de colonización y germinación), se consideran como prácticas de rutina y a menudo la metodología no es descrita en detalle en las publicaciones. La falta de precisión en los métodos convencionales pueden ocasionar la formación de artefactos o falsos negativos en su lectura. Esto motiva a proveer descripciones claras de procesos que permitan obtener imágenes de mayor calidad y precisión en la interpretación.

El presente estudio describe protocolos de preparación de esporas de MA para observación en MEB y tinción vital basada en la reacción enzimática con FDA.

\section{MATERIALES Y MÉTODOS}

A continuación se detallan los protocolos realizados para cada una de las técnicas:

\subsection{Microscopio electrónico de barrido}

\section{Esporas de HMA}

Las esporas fueron extraídas de dos cultivos monospóricos de Acaulospora colombiana y Funneliformis geosporum siguiendo el protocolo de Tamizado Húmedo propuesto por Gerdemann y Nicolson (1963), que se encuentra descrito en la página del INVAM (West Virginia University, 2016).

\section{Limpieza de esporas}

Se colocaron 20 esporas en un vaso de precipitado de $10 \mathrm{~mL}$ con una solución de Tween 20 al 3.75\% V/V. Luego se sonicó las muestras, usando un sonicador Branson 1510, en 3 series de 10 segundos con intervalos de 1 minuto. Finalmente, se filtraron las esporas con un papel filtro MN 615 y se lavaron con agua destilada para retirar los residuos de la solución jabonosa (Kaonongbua et al., 2010).

\section{Preparación de la espora y observación en el MEB}

Se colocaron las esporas de HMA una por una en la cinta doble faz de carbono con la ayuda de la pinza antiestática. Seguidamente, las muestras se dejaron en un desecador de vidrio en forma de campana por un período de 5 a 7 
días. Luego de este tiempo las muestras se situaron en un evaporador por pulverización catódica Quorum Q150R ES y se recubrieron con una capa de aproximadamente $20 \mathrm{~nm}$ de oro por 60 segundos. Finalmente se introdujeron las muestras en la cámara del MEB Tescan Mira 3 para su visualización. Los parámetros de operación variaron para cada fotografía. La información específica del voltaje, distancia de trabajo y tipo de detector se especifica al pie de cada figura.

\subsection{Tinción vital}

\section{Esporas de HMA}

Las esporas fueron extraídas de suelo de campo y de cultivos in vitro siguiendo el protocolo de Tamizado Húmedo propuesto propuesto por Gerdemann y Nicolson (1963), que se encuentra descrito en la página del INVAM (West Virginia University, 2016). Las esporas empleadas para el análisis de tinción vital tuvieron máximo tres días de extraídas del substrato.

\section{Control negativo}

Para la obtención del control negativo, se autoclavaron las esporas dos veces durante 15 minutos a $121^{\circ} \mathrm{C}$ y $25 \mathrm{PSI}$ (Firstencel et al., 1990).

\section{Observación en el microscopio de fluorescencia}

Con la ayuda de un estereomicroscopio Olympus SZ61, se colocaron las esporas extraídas en un vidrio reloj y se lo transfirió a una estufa a $27^{\circ} \mathrm{C}$ hasta que se evaporen completamente los residuos de agua. Luego se añadió $30 \mu \mathrm{L}$ de la solución de FDA (ver protocolo de preparación de soluciones) y se dejó reposar por 15 minutos en condiciones de oscuridad. Seguidamente, se transfirieron las esporas a un vidrio reloj que contenía $1 \mathrm{~mL}$ de PBS $22 \mathrm{mM}, \mathrm{pH} 7.4$ e inmediatamente se recogieron y colocaron en un porta objetos. Se procedió a observar la placa en el microscopio de fluorescencia Olympus IX53 con un filtro de excitación de 450-490 $\mathrm{nm}$ y un filtro de emisión de $520 \mathrm{~nm}$.

\subsection{Protocolo de preparación de soluciones}

\section{Solución de FDA}

La solución stock de FDA se preparó a una concentración de $0.5 \mathrm{mM}$, diluyendo $1.04 \mathrm{~g}$ en $5 \mathrm{~mL}$ de Dimetil sulfóxido (DMSO). Para la solución de trabajo se tomó $250 \mu \mathrm{L}$ de la solución stock y se aforó a $5 \mathrm{~mL}$ de buffer fosfato $(22 \mathrm{mM}, \mathrm{pH}$ 7.4). Luego, se pasó la dilución por un filtro millipore de $0.2 \mu \mathrm{m}$ y se sonicó por 60 minutos a $18^{\circ} \mathrm{C}$ en un sonicador Branson 1510. La dilución realizada en buffer fosfato no se puede almacenar. La solución stock se puede conservar durante varios 
meses a $4 \stackrel{\circ}{\circ}$; sin embargo, se recomienda verificar que no exista cambio de color (a amarillo).

\section{RESULTADOS}

\subsection{Microscopio electrónico de barrido}

Se comprobó que la limpieza de esporas es un factor que influencia el proceso de obtención de imágenes claras y precisas. Una prolongada exposición al ultrasonido puede romper las paredes de la espora, y una breve exposición puede terminar en una ineficiente limpieza (figura 1).

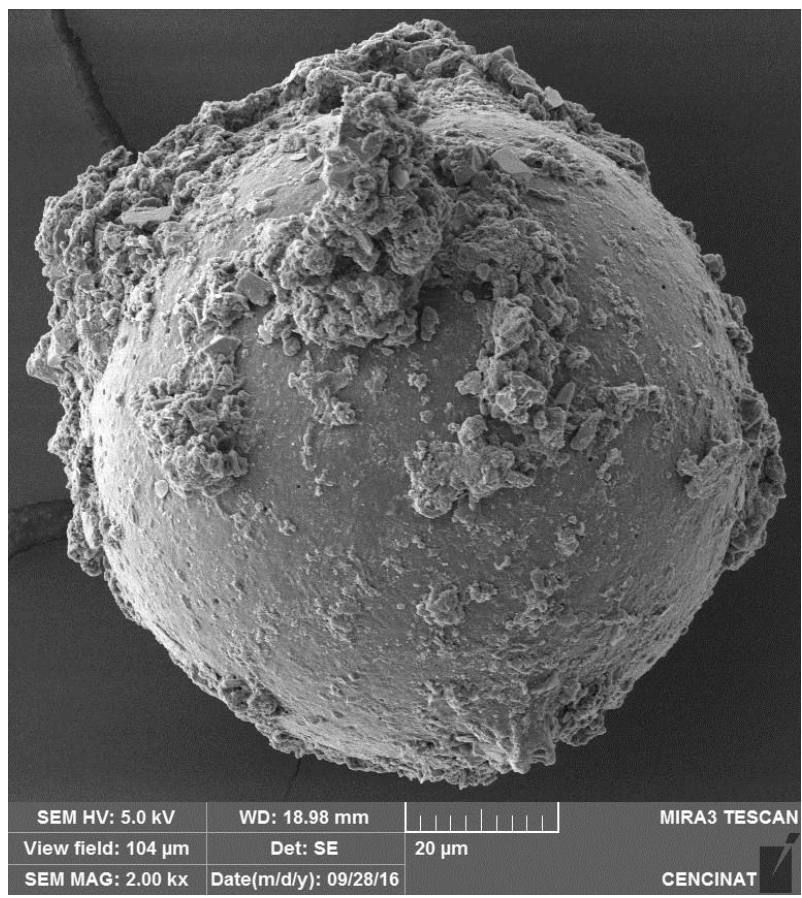

Figura 1 Micrografía de una espora de Acaulospora colombiana con impurezas.

La deshidratación de las esporas se realizó en un desecador de vidrio completamente limpio y desinfectado. Los microfotografías mostraron que el método es adecuado para deshidratar las esporas sin deformar sus estructuras (figura 2).

En las microfotografías se visualizó la presencia de pequeños agujeros en las esporas (figura 2A). La pared de las esporas pertenecientes a Acaulospora colombiana se observaron lisas (figura $2 \mathrm{~A}$ ), mientras que las de Funneliformis geosporum se presentaron rugosas (figura 2B). 

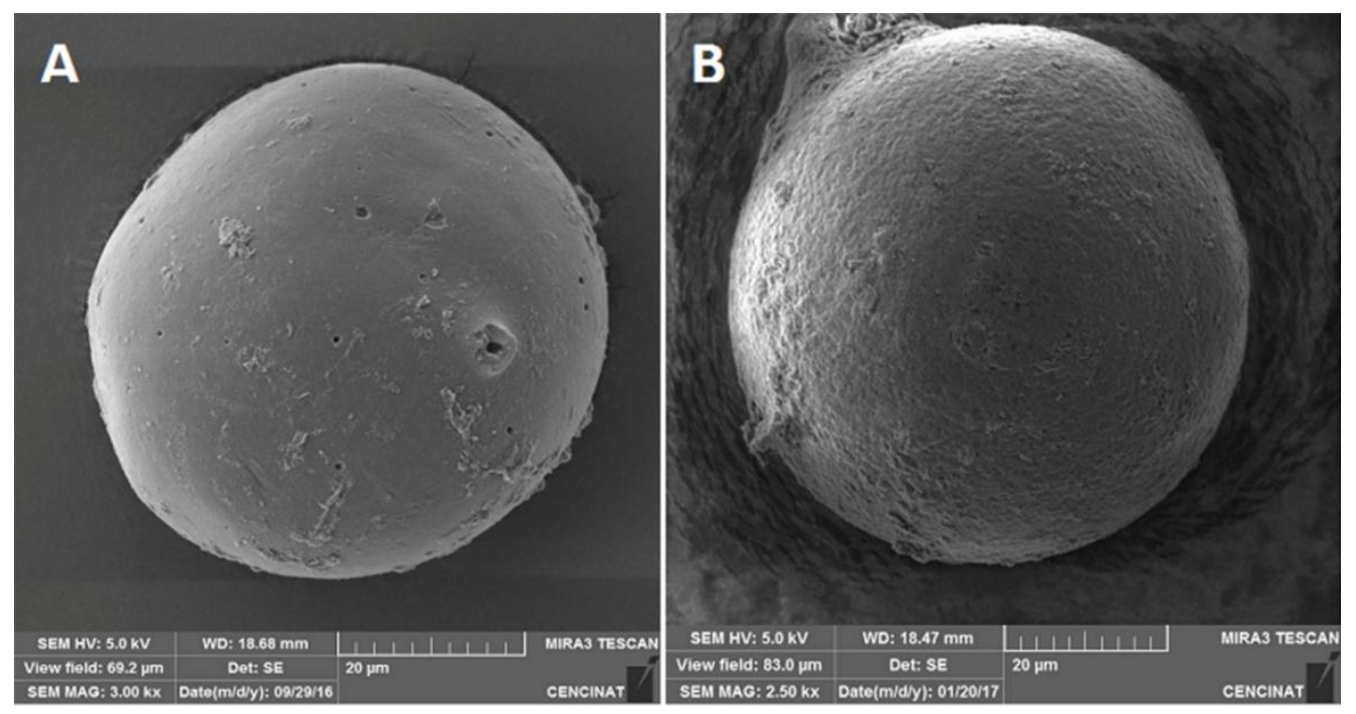

Figura 2 Micrografías de esporas de MA con diferentes tipos de pared. A: espora de Acaulospora colombiana con pared lisa. B: espora de Funneliformis geosporum con pared rugosa.

\subsection{Tinción vital}

Se observó que la limpieza tanto de las esporas como de las placas, es un factor muy importante, debido a que las impurezas pueden distorsionar u opacar la fluorescencia (figura 3).
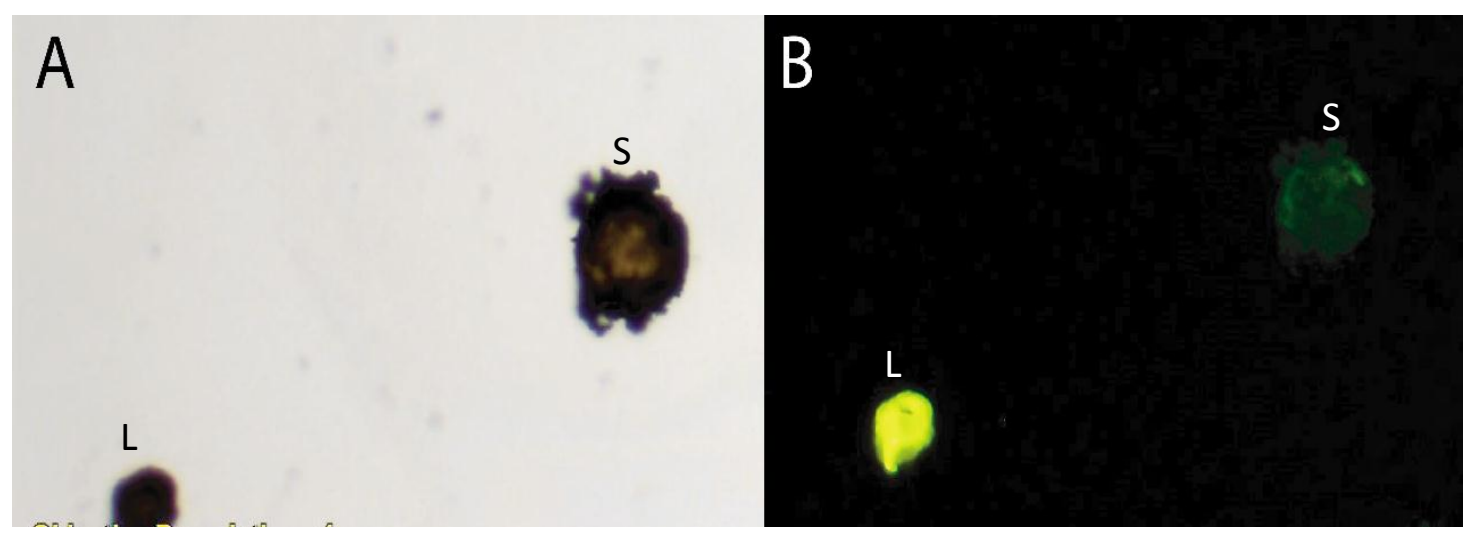

Figura 3 Esporas teñidas con una solución de FDA $(25 \mu \mathrm{M})$ observadas en el microcopio Olympus IX53. A: esporas de MA limpias (L) y con impurezas (S) en campo claro 10X. B: Esporas de MA limpias (L) y con impurezas (S) utilizando el filtro BW 10x. 
Las fotografías evidenciaron que las esporas presentan una variación del color de la fluorescencia (figura 4: A y B) y también autoflorescencia (figura 4C).

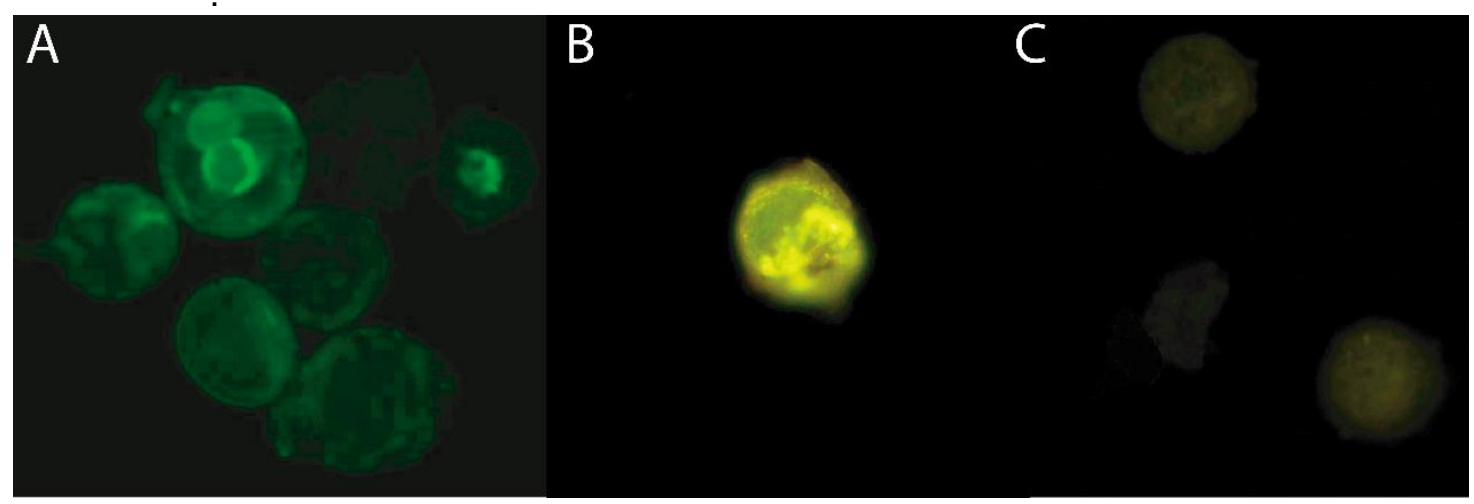

Figura 4 Esporas de MA teñidas con una solución de FDA $(25 \mu \mathrm{M})$ observadas en el

\section{DISCUSIÓN}

La estandarización de las metodologías de preparación de muestras disminuye las alteraciones o falsos positivos, reduce la variabilidad y por lo tanto incrementa la confiabilidad de los resultados obtenidos (Calich et al., 1978). El mejoramiento de técnicas reportadas en trabajos previos permite dar solución a los problemas generados de acuerdo a las necesidades de cada investigador, ya que los procedimientos difieren dependiendo el tipo de muestra y las condiciones ambientales a las que son sometidas (Dykstra y Reuss, 2003). A continuación se presenta la discusión de resultados obtenidos en el desarrollo de los protocolos presentados en este estudio.

\subsection{Microscopio electrónico de barrido}

Los requerimientos de preparación para los especímenes que van a ser observados en el MEB son rigurosos y toman demasiado tiempo en comparación con los de otros microscopios. La preparación de la muestra comienza con la selección del adecuado material biológico y procede con la fijación y deshidratación (Koehler, 1973).

Las técnicas utilizadas con mayor frecuencia para la observación de estructuras micorrízicas son el secado hasta el punto crítico y el secado por criofijación. El secado hasta el punto crítico emplea etanol y acetona para la deshidratación, tetraóxido de osmio para la fijación y CO2 líquido (Calderoni et al., 2003; Cuenca y Herrera-Peraza, 2008). La criofijación emplea nitrógeno líquido y 
liofilización (McCully et al., 2000; Ryan et al., 2003). En los últimos años, se ha desarrollado la técnica de ESEM (Modo ambiental del MEB) que permite observar las muestras en su estado natural sin necesidad de aplicar deshidratación y fijación; pese a ello, el desarrollo del método requiere de una gran experticia por parte del investigador (Pathan et al., 2010).

La deshidratación de la muestra es una etapa fundamental para su observación en el MEB, debido a que la presencia de agua produciría una perturbación del haz de electrones por su inestabilidad bajo vacío (Dunlap y Adaskaveg, 1997). En este ensayo se empleó un descador de vidrio para la realización de este proceso,resultando en una baja alteración de las estructuras. La ventaja de aplicar esta técnica es que no requiere de cambios constantes de soluciones (etanol del 30 al 90\%, glutaraldehído, tetraóxido de osmio, acetona) en comparación con las técnicas de criofijación y punto crítico (Unda, 2015), brindando mayor facilidad para el investigador.

Los resultados mostrados en las fotografías de la figura 2, evidencian la presencia de agujeros en la pared de las esporas, que puede deberse a las características de ciertas especies, o a lisis de la pared de la espora por la presencia de bacterias (Roesti et al., 2005). Los cambios de contextura observados en la pared de la espora, lisa o rugosa, depende de la especie de MA (Walker, 1983).

\subsection{Tinción vital}

Las esporas con más de 3 días de almacenamiento disminuyen su vitalidad, ya que las condiciones de estrés podrían producir que entren en un estado de latencia o senescencia (Tommerup, 1983). Por este motivo, en la estandarización del protocolo presentado en este estudio se emplearon esporas que tenían máximo 3 días de extraídas del substrato.

El empleo de diferentes especies de MA provocó una variación del color de la fluorescencia en esporas vitales, puesto que se ha demostrado que el producto de almacenamiento de ciertas especies es el glucógeno o algún otro material no lipoideo carente de enlaces éster. Esto produce una disminución en la presencia de enzimas estereasas, las cuales son responsables de la hidrólisis del FDA (Miller, Torres et al., 1993).

Por otra parte, se evidenció que las esporas muestran una autoflorescencia (figura 4). Esta característica se produce por la presencia de cromóforos endógenos en las células (Wieczorek, 2008), provocando que fluorezcan en su estado natural sin necesidad de tratarlas con un fluoróforo. Estudios previos han reportado que las esporas de MA autofluorescen cuando son sometidas a emisiones de luz verde y azul (Dreyer et al., 2006), lo que explica la detección de este parámetro en el ensayo. 
La ausencia de fluorescencia se interpretó como no vitalidad o latencia de la espora, debido a que esta etapa se caracteriza por presentar cambios en la pared, haciéndola impenetrable (Mosse, 1970). Dicha condición impide el paso del FDA a través de la membrana y consecuentemente no se produce fluorescencia.

Un alto nivel de viabilidad y uniformidad en los resultados se obtuvieron con esporas producidas in vitro, los mismos que se atribuyen a que en el cultivo in vitro se mantienen controladas las condiciones ambientales y no se presentan limitaciones de crecimiento, consecuentemente las esporas son menos susceptibles a la mortalidad o senescencia (Meier y Charvat citado por Marleau et al., 2011). Las características más comunes que presentan las esporas de campo son: variabilidad en estado fenológico, presencia o ausencia de peridio (capa externa que va desarrollándose dependiendo la edad de la espora) y variación de factores ambientales (humedad, nutrientes, temperatura) (Meier y Charvat, 1993). De manera que, el método descrito funciona de mejor manera con esporas cultivadas in vitro.

Aplicar la técnica de tinción vital con FDA requiere de 1 a 2 horas, razón por la cual se considera rápida y de fácil desarrollo a diferencia de otros métodos existentes. Por ejemplo, el NMP mide la presencia o ausencia de micorrizas con probabilidades estimadas del número de propágulos en una tabla estadística (Bansal y Mukerji, 2002). Los datos se toman empleando suspensiones diluidas de muestras de suelo y poseen un alto intervalo de confianza (95\%) incluso con un factor de dilución bajo, por lo que se necesita de muchos tubos de replicación (West Virginia University, 2016). El porcentaje de colonización en cambio es un método laborioso que consiste en el conteo de presencia de micorriza en la raíz de la planta huésped dividida por secciones, por tal motivo requiere de $14-30$ días de inoculación para asegurar que la raíz esté infectada con HMA (Franson y Bethlenfalvay, 1989).

\section{CONCLUSIONES}

Los resultados del presente estudio demuestran que el tratamiento de limpieza con Tween 20 y deshidratación en desecador de vidrio es adecuado para la observación de esporas de HMA en el MEB, debido a que se reducen al mínimo los artefactos y se conservan perfectamente las estructuras generando micrografías claras y precisas.

La aplicación de tinción vital con FDA tiene mayor precisión en esporas producidas in vitro; sin embargo, se debe tener cuidado en la interpretación de los resultados ya que las esporas en latencia, al igual que las no vitales, no presentan fluorescencia. 
Las técnicas descritas en este trabajo facilitan en gran medida los procesos de indentificación morfológica de especies de MA y la determinación de vitalidad en las esporas, los cuales son parámetros comúnmente evaluados en las investigaciones concernientes a hongos micorrízicos. Los protocolos desarrollados son prácticas simples, eficientes y confiables para análisis de esporas de micorriza arbuscular.

\section{AGRADECIMIENTOS}

A la Ing. Andrea Vaca por la valiosa ayuda y asesoría en el manejo y obtención de las imágenes en el microscopio electrónico de barrido. Al Dr. Marcelo Grijalva porque nos permitió utilizar el microscopio de fluorescencia.

\section{REFERENCIAS}

1. Bansal, M., y Mukerji, K. G. (2002). Methods in Study of Viability of VAM Fungal Spores. En K. G. Mukerji, C. Manoharachary, y B. P. Chamola, Techniques in Mycorrhizal Studies (págs. 217-229). Delhi: Springer Science.

2. Blaszkowski, J. (2003). Arbuscular mycorrhizal fungi (Glomeromycota), Endogone, and Complexipes species deposited. Disponible en: http://www.zor.zut.edu.pl/Glomeromycota/Life\%20cycle,\%20significance\% 20and\%20properties\%20of\%20AM.html

3. Calderoni, M., Sieber, T., y Holdenrieder, O. (2003). "Stereum sanguinolentum: It is an amphitallic basidiomicete?". Mycologia, 95(2), 232238.

4. Calich, L. G., Purchio, A., y Paula, C. R. (1978). "A new fluorescent viability test for fungi cells". Mycopathologia, 66(3), 175-177.

5. Cuenca, G., y Herrera-Peraza, R. (2008). "Scutellospora striata sp.nov., a newly described glomeromycotan fungus from La Gran Sabana". Mycotaxon, 105, 79-87.

6. Dreyer, B., Morte, A., Pérez-Gilabert, M., y Honrubia, M. (2006). "Autoflorescence detection of arbuscular mycorrhizal fungal structures in palm roots: an underestimated experimental method". Mycological Research, 110, 887-897. Disponible en: https://www.ncbi.nlm.nih.gov/pubmed/16893637

7. Dunlap, M., y Adaskaveg, J. E. (1997). Introduction to the Scanning Electron Microscope. (U. o. Merced, Ed.) Disponible en: https://imf.ucmerced.edu/downloads/semmanual.pdf 
8. Dykstra, M. J., y Reuss, L. E. (2003). Biological Electron Microscopy: Theory, Techniques, and Troubleshooting. Disponible en: http://www.springer.com/gp/book/9780306477492

9. Firstencel, H., Butt, T. M., y Carruthers, R. I. (1990). "A Fluorescence Microcopy Method for Determining the Viability of Entomophthoralean Fungal Spores". Journal of Invertebrate Pathology, 55, 258-264.

10.Flores, C., Hassan, M., Corkidi, G., Galindo, E., y Serrano-Carreón, L. (2003). "Determinación de la Viabilidad de Biomasa Micelial de Trichoderma harzianum". Morelos, México: Universidad Autónoma de México.

11.Franson, R. L., y Bethlenfalvay, G. J. (1989). "Infection unit method of vesicular-arbuscular mycorrhizal propagule determination". Soil Sci. Soc. Am. J, 53, 754-756.

12.Gerdemann, J. W., y Nicolson, T. H. (1963). "Spores of mycorrhizal endogone species extracted from soil by wet-sieving and decanting". Transactions of the British Mycological Society, 46, 235-244.

13.Goverde, M., Van Der Heijden, M. A., Wiemken, A., Sanders, I. R., y Erhardt, A. (2000). "Arbuscular mycorrhizal fungi influence life history traits of a lepidopteran herbivore". Oecologia, 125, 362-369. Disponible en: http://link.springer.com/article/10.1007\%2Fs004420000465.

14.Kaonongbua, S. G., Morton, J., y Bever, J. (2010). "Taxonomic revision transferring species in Kuklaspora to Acaulospora (Glomeromycota) and a description of Acaulospora colliculosa sp.nov. from field collected spores". Mycologia, 102(6), 1497-1509.

15.Koske, R. E. (1985). "Glomus aggregatum emended: A distinct taxon in the Glomus fasciculatum complex". Mycologia, 77, 619-630.

16.Marleau, J., Dalpé, Y., St-Arnaud, M., y Hijri, M. (2011). "Spore development and nuclear inheritance in arbuscular mycorrhizal fungi". BMC Evolutionary Biology, 11, 1-11. Disponible en: http://bmcevolbiol.biomedcentral.com/articles/10.1186/1471-2148-11-51

17.McCully, M., Shane, M., Baker, A., Huang, C., Ling, L., y Canny, M. (2000). "The realiability of cryoSEM for the observation and quantification of xilem embolism and quantitative analysis of xilem sap in situ". Journal of Microscopy, 198(1), 24-33. Disponible en: http://onlinelibrary.wiley.com/doi/10.1111/j.1469-8137.2006.01825.x/full

18.Meier, R., y Charvat, I. (1993). "Reassessment of tetrazolium bromide as a viability stain for spores of vesicular-arbuscular mycorrhizal fungi". American Journal of Botany, 80(9), 1007-1015. 
19.Meijering, E., Carpenter, A. E., Hamprecht, F. A., y Olivo-Marin, J. C. (2016). "Imagining the future of bioimage analysis". Nature Biotechnology, 34(12), 1250-1255.

20.Miller, S., Torres , P., y McClean, T. M. (1993). "Basidiospore viability and germination in ectomycorrhizal and saprotrophic basidiomycetes". Mycol. Res, 97(2), 141-149.

21.Mosse, B. (1970). "Honey-Coloured, Sessile Endogone Spores". Arch. Mikrobiol, 74, 146-159. Disponible en: http://link.springer.com/article/10.1007/BF00412208

22.Remy, W., Taylor, T., Hass, H., y Kerp, H. (1994). "Four hundred-millionyear-old vesicular arbuscular mycorrhizae". Proc. Natl. Acad. Sci. 91, 1184111843. Disponible en: www.pnas.org/content/91/25/11841.full.pdf

23.Roesti, D., Ineichen, K., Braissant, O., Redecker, D., Wiemken, A., y Aragno, M. (2005). "Bacteria associated with spores of the arbuscular mycorrhizal fungi Glomus geosporum and Glomus constrictum". Applied and Environmental Microbiology, 71(11), 6673-6679. Disponible en: http://aem.asm.org/content/71/11/6673.full

24.Ryan, M., McCully, M., y Huang, C. (2003). "Location and quantification of phosphorus and other elements in fully hydrated, soil-grown arbuscular mycorrhizas: a cryo-analytical scanning electron microscopy study". New Phytologist, 160, 429-441.

25.Savidge, T., y Pothoulakis, C. (2005). Methods in Microbiology (Vol. 34). Elsevier. Disponible http://www.sciencedirect.com/science/bookseries/05809517

26.Schnûrer, J., y Rosswall, T. (1982). "Fluorescein Diacetate Hydrolysis as a Measure of Total Microbial Activity in Soil and Litter". Applied and Enviromental Microbiology, 43(6), 1256-1261.

27.Singh, R. P., y Singh, U. S. (1995). Molecular Methods in Plant Pathology. Lewis Publishers. Disponible en: https://books.google.com.ec/books?id=fBbHz5-

IINoC\&pg=PA57\&lpg=PA57\&dq=fluorescence+protocols+fungi\&source=bl \&ots=l8VB6pRXTQ\&sig=2dFZ5N8orvaZwme0j2s99BgFU8s\&hl=es\&sa=X\& ved=0ahUKEwiYltK3_ffRAhWGZCYKHeFhDwMQ6AEINjAD\#v=onepage\& $\mathrm{q}=$ fluorescence $\% 20$ protocols\%20fun

28.Stahl, P. O., y Smith, W. K. (1984). "Effects of different geographic isolates of Glomus on the water relations of Agropyron smithii". Mycologia, 261-267.

29.Tommerup, I. C. (1983). "Spore dormancy in vesicular-arbuscular mycorrhizal fungi". Trans. Br. mycil. Soc., 81(1), 37-45. Disponible en: http://www.sciencedirect.com/science/article/pii/S0007153683802010 
30.Unda, M. (2015). Caracterización Morfológica de tres especies de Micorrizas Arbusculares (tesis de pregrado). Universidad de las Fuerzas Armadas-ESPE, Sangolquí, Ecuador.

31.Walker, C. (1983). "Taxonomic concepts in the Endogonaceae; spore wll characteristics in species descriptions". Mycotaxon, 18, 443-455.

32.West Virginia University. (19 de Agosto de 2016). INVAM. Disponible en: http://invam.wvu.edu/methods/spores/spore-extraction

33.Wieczorek, A. (2008). "Autoflorescence of ascospores and conidial spores in selected lichen species of the Opegrapha genus". Acta Mycologica, 43(1), 99-103.

34.Xiaohong, H., y Koide, R. (1994). "The effects of mycorrhizal infection on components of plant growth and reproduction". New Phytol, 128, 211-218. Disponible en: http://onlinelibrary.wiley.com/doi/10.1111/j.14698137.1994.tb04004.x/pdf. 